\title{
Controle: perspectivas de análise na teoria das organizações
}

\section{Control and business theory: perspectives of study.}

\author{
Fernando Ramalho Martins*
}

\section{Resumo}

Este artigo tem por objetivo promover uma discussão acerca do controle na teoria das organizações. Nesse sentido, definiremos o termo a partir de duas diferentes perspectivas, uma de cunho funcionalista, com ênfase nos aspectos coordenativos e funcionais do controle em relação ao organismo organizacional, e uma segunda de cunho crítico, enfatizando a explicitação das contradições sociais inerentes ao fenômeno. Em meio a essa discussão, apresentaremos a economia política do poder por considerar que essa corrente de pensamento é uma das poucas, nos estudos organizacionais, a abordar a temática em conformidade com a segunda perspectiva.

Palavras-chave: controle; teoria das organizações; economia política do poder.

\section{Abstract}

This paper aims to present a discussion about control theory in organization studies. In order to do it, we will propose two perspectives: one focused in coordinative and functional aspects of control in organization; and another focused in contradiction and in social aspects of the organizational control. The first is the traditional point of view in organizational theory and will be named Functionalist Perspective and the second will be named Critical Perspective, and is a non traditional point of view in this field of study. To represent the second perspective we will present an organizational theory called "Power Political Economy".

Keywords: Control; organizational theory; Power Political Economy

\section{Introdução}

O controle é uma temática central nos estudos organizacionais, como nos mostram Motta (1979), Jermier (1998), Tannenbaum (1975), Etzioni (1967) e Faria (1985). Conforme defende Jermier (1998), o controle pode ser encontrado em qualquer lugar onde pessoas unam forças em nome de uma ação organizada. Assim, na história da humanidade, diversas configurações de controle têm sido usadas para direcionar ações em um sentido ou outro; por isso, o controle está diretamente relacionado com nossos maiores triunfos e tragédias.

Por ser uma temática complexa, podemos encontrar diferentes enfoques utilizados para abordá-la. Dessa forma, certos aspectos relacionados com esse fenômeno ora são destacados, ora são ocultados. De modo geral, o enfoque funcionalista tem sido o grande norteador das análises nos estudos organizacionais.

De acordo com Davel e Alcadipani (2003), a partir da década de 1970, diferentes abordagens surgiram como alternativa a essa perspectiva. Dentre elas, os autores destacam a perspectiva crítica. Todavia, essa tendência de desenvolvimento da perspectiva crítica ainda é um tanto quanto restrita em termos de produção nacional, dado que conforme um levantamento realizado por esses autores, apenas $2 \%$ dos artigos publicados nos principais periódicos nacionais de administração durante os anos 1990 apresentaram uma visão crítica.

\footnotetext{
- Mestre em Administração pela Universidade Federal do Paraná-UFPR. Professor da Faculdade de Agudos-FAAG/São Paulo. Endereço: Av. Duque de Caxias, 24-85 - bl. C - Ap. 34 - Bauru - SP - Brasil - - CEP 17011-066. E-mail: ramartins@ig.com.br.

Artigo recebido em em abril de 2005 e aceito para publicação em novembro de 2005.
} 
Tendo em vista a importância do tema e a predominância da perspectiva funcionalista nos estudos organizacionais, neste artigo buscaremos realizar um movimento duplo, pelo qual se tentará definir o conceito de controle a partir de duas diferentes perspectivas de análise, as quais serão denominadas organizacional-funcionalista e sociológico-crítica. Acompanhando esse movimento, buscaremos evidenciar nosso posicionamento diante dessas perspectivas.

Quanto ao segundo movimento. acreditamos que contribuirá para fortalecer a perspectiva crítica no campo organizacional. Tal fortalecimento é de suma importância, pois, a nosso ver, a quase inexistência de reflexões de cunho crítico vem tornando o administrador um mero reprodutor de técnicas gerencialistas. A perspectiva crítica, ao contrário da anterior, dá subsídio a uma reflexão social e política e, por isso, deve ser resgatada do âmbito da teoria das organizações. Consideramos que tais reflexões acompanham Motta (1986, p.57) quando este afirma que:

O fato de vivermos em uma época que celebra a técnica de todas as formas é particularmente evidente e nocivo nas ciências sociais, em geral, e na teoria das organizações aplicadas à empresa, ao Estado e à escola em particular.

[...] O estudioso das organizações deve, antes de mais nada, estar atento às razões e às conseqüências do tipo de pesquisa em que se envolve, ao tipo de conhecimento que produz e a quem esse conhecimento serve.

\section{Perspectiva organizacional-funcionalista}

Antes de entrarmos no conceito de controle segundo essa perspectiva, faz-se necessária uma breve discussão sobre o conceito de função. Para entendermos tal conceito(e sua apropriação pelo campo das ciências sociais), é preciso direcionar nosso pensamento para o sociólogo Durkheim (1978) e para os antropólogos Malinowisk (1978) e Radcliffe-Brown (1973).

Durkheim (1978) apresentou a idéia de função nos estudos sociais, ao estudar a divisão do trabalho na sociedade "moderna" e a conseqüente solidariedade orgânica trazida por essa. Essa idéia resultou de uma aproximação entre o organismo biológico e o entendimento do social. Nesse sentido, parte-se do pressuposto de que, ao estudar a realidade, o cientista social deve estar atento às diversas partes que compõem o corpo social e, principalmente, às funções desempenhadas por essas partes. Dessa maneira, em linhas gerais, ao investigar a função da divisão social do trabalho, Durkheim (1978) queria entender qual necessidade ela cumpre ante o todo social.

De forma semelhante, na antropologia, podemos destacar o polonês Malinowski (1978), com suas pesquisas antropológicas realizadas nos arquipélagos da Nova Guiné (Ilhas Trobriand). Nesse famoso estudo, duas contribuições podem ser destacadas: o método da observação participante ${ }^{1}$ e a utilização do conceito de função e dos postulados do funcionalismo, de forma geral.

Ainda dentro da antropologia, seguindo essa corrente de pensamento, podemos destacar Radcliffe-Brown (1973). Tal autor é, a nosso ver, um dos que definiram de forma mais clara o termo "função". A exemplo de Durkheim (1978), o sentido atribuído a esse termo deriva da analogia entre vida social e vida orgânica. Dessa forma, para Radcliffe-Brown (1973), o termo está relacionado ao papel desempenhado pelas instituições sociais $^{2}$ em termos de necessidades de sobrevivência do organismo social, objeto de estudo das ciências sociais. Assim, a noção de organismo passa a ser empregada como uma analogia para se compreender o corpo social. As unidades integrantes do organismo desempenham atividades, ou melhor, funções pelo todo, assegurando com isso sua sobrevivência. A título de exemplificação, cada órgão humano tem uma determinada tarefa ou função para com a continuidade do todo orgânico. Como pode ser observado, isso leva a uma visão que volta suas atenções para a manutenção do atual e não para a sua superação. Nas palavras de Burrell e Morgan (1979, p. 26 - tradução nossa), referindo-se ao funcionalismo:

\footnotetext{
${ }^{1}$ Em relação ao uso da observação participante como metodologia de pesquisa nos estudos organizacionais, ver Serva e Jaime Júnior (1995).

${ }^{2}$ Aqui, o termo "instituição social” é definido de uma perspectiva antropológico-sociológica e não, organizacional.
} 
usualmente está relacionado à uma filosofia da engenharia social como base da mudança social e enfatiza a importância de entender a ordem, o equilíbrio e a estabilidade na sociedade e a maneira como isso pode ser mantido. Ele está relacionado com a efetiva 'regulação' e controle dos problemas sociais.

Como mostra Demo (1995), o "sistemismo" aparece como abordagem complementar ao enfoque funcionalista, ou segundo as palavras do autor (p.203) "em parte o sistêmico continua o espírito do funcionalismo, sobretudo na tentativa de se conservar dinâmico, embora encerrado no horizonte do sistema". Dessa perspectiva, o sistema é tido como um todo composto por partes interdependentes. Somado a essas idéias, o fenômeno da autoregulação sistêmica dá o suporte necessário para os teóricos funcionalistas abordarem a temática do controle. Para Demo (1995), esses pressupostos possibilitam um certo dinamismo à perspectiva funcionalista, que destoa do formalismo característico.

O cientista que trabalha dessa perspectiva funcional-sistêmica, ao voltar-se para o sistema, também pode direcionar sua análise para as anomalias e conflitos, que são, contudo, sempre passageiros e reguláveis. O controle, portanto, aparece como a ferramenta necessária para regular o sistema ao seu estado normal.

O fato de considerar as anomalias e conflitos do sistema no limite pode até mesmo conferir um caráter pseudocrítico e pseudodialético a essa perspectiva. Contudo, um olhar efetivamente crítico implica as noções de contradição e de superação dialética, incompatíveis com essa visão sistêmica. Conforme coloca Demo (1995, p.215):

Por definição, todo conflito é regulável se partirmos da idéia fundamental de que sistema é o todo que se auto-regula. Nisso não é dialético, ou o é pela metade, como a dialética não antagônica [...] Certamente, todo conflito será por definição solucionável porque não se considera a possibilidade de superação do sistema.

Nas ciências sociais, Parsons (1969) é tido como um exemplo clássico dessa perspectiva. Seguindo a tradição funcionalista, essa autor herdou: "de Pareto [...], a idéia de 'equilíbrio'; de Durkheim, a idéia de 'anomia', ou comportamento desviado; de Weber, a idéia de 'ação social'; da escola inglesa, a idéia ligada à analogia do organismo." (DEMO, 1995, p. 222)

De forma geral, em Parsons (1969) estão fortemente presentes as idéias de função, sistema e de auto-regulação sistêmica, bem como a crença numa ordem geral comum, subjacente aos fenômenos, o que permite a utilização de esquemas explicativos básicos no entendimento dos fenômenos sociais.

A título de exemplificação, na obra Sociedades, Parsons (1969) objetiva apresentar um estudo da evolução societária a partir de uma perspectiva comparativa e evolutiva, e ao evidenciar os pontos norteadores de sua empreitada, deixa claro os traços anteriormente evidenciados:

Essa classificação de quatro subsistemas de ação humana [sistema social, organismo comportamental, personalidade individual e sistema cultural] é uma aplicação de um esquema geral que pode ser usado para analisar os sistemas sociais. Esse esquema analisa qualquer sistema de ação através das quatro categorias seguintes: 1. a que se refere à manutenção dos padrões mais elevados que controlam ou 'governam' o sistema, 2. a integração interna do sistema, 3. sua orientação para realização de objetivos com relação a seu ambiente e 4. sua adaptação mais generalizada às condições amplas do ambiente [...]. No interior do sistema de ação, os sistemas culturais se especializam em torno da função de manutenção de padrão; os sistemas sociais, em torno da integração de unidades de ação (indivíduos humanos ou, mais precisamente, personalidades comprometida com papéis); os sistemas de personalidade, em torno da realização de objetivos; o organismo comportamental em torno da adaptação. (PARSONS, 1969, p.19)

Essa maneira de ver a realidade se estende a outras áreas como, por exemplo, a administração. Aliás, de forma geral, a própria história dos estudos em administração é marcada por esse ponto de vista, segundo aponta Demo (1995, p.214) 
Dentro das ciências sociais, certamente é a administração (pública e empresarial) que maior proveito tirou dessa metodologia, porque, mais que as outras, coloca como centro das atenções o problema básico da organizabilidade social.

Hatch (1997, p.327), por exemplo, afirma que "na moderna teoria organizacional, o controle organizacional é definido como um mecanismo de implementação da estratégia". A nosso ver, a idéia de estratégia e de mecanismos trazem em seu bojo as implicações anteriormente descritas. Antes de tudo, porque a idéia de estratégia está relacionada com a idéia de sistema (OLIVEIRA,2003; WRIGHT, KROLL e PARNELL, 2000); isto é, com a idéia de que a organização é um todo orgânico ${ }^{3}$ que mantém relação com um ambiente instável. Além disso, a palavra "mecanismo", no sentido anteriormente empregado, pode ser substituída pela expressão "aquilo que tem o papel ou a função de assegurar". Dessa forma, encontramos aqui a idéia de organização como um sistema composto de subsistemas (entre eles, o subsistema de controle) cujo papel é lutar pela sua sobrevivência através do processo de adaptação. Nesse contexto, o controle é aquilo que tem a função de garantir a adaptação.

Seguindo esse pensamento, Tannenbaum $(1975)^{4}$ define controle como uma consequiência inevitável da sociedade organizacional, como aquilo que assegura a manutenção e a sobrevivência da organização.

o processo de controle ajuda a restringir o comportamento idiossincrático e a mantê-lo de acordo com o plano racional da organização. Compete à função de controle estabelecer a conformidade com as exigências organizacionais e realizar os objetivos supremos da organização. A coordenação e a ordem criadas pelos diversos interesses e comportamentos potencialmente difusos dos membros são, em grande parte, uma função do controle. É nesse ponto que surgem muitos dos problemas do funcionamento da organização e dos ajustamentos individuais. (TANNENBAUM, 1975, p.16)

É importante ressaltar que o termo, para esse autor (e para outros autores no âmbito das teorias organizacionais), aproxima-se do conceito de poder, conforme observa Silva (2000, p.3) ao citar Tannenbaum (1975):

o conceito de controle está intimamente relacionado àquele de poder, no sentido de que ele pressupõe a ação de alguém ou algo sobre o comportamento de outro. Mesmo não o fazendo de maneira explícita, os autores do controle, ao tratarem do tema, fazem referência ao poder.

Tal afirmativa corrobora o que é defendido por Tannenbaum (1975, p.18), conforme pode ser notado nesta passagem:

empregaremos o termo [controle] nesse sentido, para nos referirmos a qualquer processo no qual uma pessoa, grupo de pessoas ou organizações de pessoas determinam, i. e., intencionalmente afetam, o comportamento de outra pessoa, grupo ou organização.

Hatch (1997) - uma importante pesquisadora dos estudos organizacionais -, ao discorrer sobre essa temática na teoria organizacional modernista, ${ }^{5}$ apresenta um interessante esboço contemplando análises que se enquadram nessa perspectiva. Segundo essa autora, tais estudos partem do pressuposto de que os indivíduos têm diferentes razões para participar da organização. Assim, o controle aparece como um mecanismo ou instrumento administrativo cuja função é assegurar o alcance das metas e objetivos organizacionais, de preferência, pela conciliação de objetivos divergentes. Ainda de acordo com essa corrente, a autora destaca três teorias: a do modelo cibernético, a teoria da agência e a teoria do mercado, burocracia e clãs.

A primeira define controle organizacional a partir da analogia com um termostato ${ }^{6}$ e, portanto, estabelece uma relação entre o ato de ajustamento e a regulação do organismo organizacional.Portanto, o controle organizacional deriva da comparação dos resultados obtidos com os resultados desejados. A partir dessa comparação, a

\footnotetext{
${ }^{3}$ Morgan (1999) também dá indícios de que as raízes do pensamento estratégico estão na imagem da organização como um organismo.

${ }^{4}$ Renomado estudioso que foi professor e pesquisador da Universidade de Michigan.

${ }^{5} \mathrm{Na}$ referida obra, a autora discute as teorias organizacionais a partir de três perspectivas: a modernista, a simbólico-interpretativista e a pós-modernista. Para os fins visados, levaremos em conta apenas o que se relaciona à primeira perspectiva, visto representar a grande maioria dos estudos "clássicos" na área organizacional.

${ }^{6}$ Dispositivo destinado a manter constante a temperatura de um sistema.
} 
administração terá subsídios para implantar as ações gerenciais de controle que visam manter o sistema organizacional na "temperatura" desejada, planejada ou "ideal"; ou seja, o controle abarca todo o processo de correção de rumos, tendo início na identificação das disfunções organizacionais e fim nas ações corretivas.

Na teoria da agência, segundo Hatch (1997), a questão do controle é vista a partir da relação entre o "principal" (proprietários/acionistas) e os "agentes" (gerentes/administradores). Nessa teoria, a atenção volta-se para as maneiras de se controlar o comportamento do "agente" de forma a assegurar que o interesse do "principal" esteja garantido; ou seja, o controle é concebido como uma ferramenta gerencial cuja função é conciliar interesses divergentes (da forma mais harmônica possível). Vale ressaltar que embora essa teoria "enxergue" uma relação conflituosa entre principal e agente, sua atenção - como é característico do referencial funcionalista - volta-se para a harmonização ou, então, para a coordenação dessa relação, tendo em vista assegurar que a consecução dos objetivos do principal prevaleça ante o agente.

Por fim, na terceira teoria, "mercado, burocracia e clãs", o controle é definido como aquilo que assegura a cooperação entre indivíduos que partilham de objetivos divergentes. Nessa discussão, são defendidas três fontes de controle usadas pela organização para assegurar essa cooperação mútua: o mercado, a burocracia e o clã. De maneira resumida, pode-se dizer que o controle de mercado se dá pela competição entre empresas ou entre departamentos e indivíduos. O controle da burocracia ocorre a partir de um conjunto de normas, regras, procedimentos de conduta e fiscalização. Quanto ao do clã, verifica-se pelo compartilhamento de valores, crenças e expectativas.

A partir do exposto, constatamos que dessa perspectiva, a questão do controle é sempre analisada como um ferramenta, ou melhor, como um componente ou uma parte do corpo organizacional que, em última instância, assegura a cooperação entre seus membros e direciona a organização para a correta adaptação diante do meio, atendendo, assim, às suas necessidades de sobrevivência.

Além disso, de forma geral, conforme colocam Chanlat e Sèguin (1987), nas concepções apresentadas anteriormente, podem ser destacados quatro traços quanto aos estudos referentes a esse paradigma funcionalista: a visão sistêmica, a teleologia, a concepção integradora e a "a-historicidade". Nesse sentido, o controle é definido a partir de uma visão que compreende a organização como um sistema composto por partes interdependentes (visão sistêmica), cuja existência depende de um conjunto de relações coordenadas. A organização torna-se, então, um conjunto de esforços coordenados (concepção integradora). Além disso, parte-se do pressuposto de que tais esforços são orientados para o alcance de certos objetivos e metas que são (ou deveriam ser) comuns a todos os membros organizacionais (visão teleológica). Como conseqüência desse percurso temos a quarta característica, a "a-historicidade"; ou seja, a tendência em desconsiderar o caráter histórico das relações de poder e controle, reificando as formas atuais de controle e encobrindo os seus efeitos numa escala mais ampla.

As principais limitações dessa perspectiva estão, primeiro, no fato de que ela, por estar centrada na organização e nas necessidades organizacionais, oculta as questões relativas ao caráter opressor e alienante do controle, bem como suas outras consequiências prejudiciais ao todo social. Uma segunda limitação, conforme dito antes, refere-se ao já mencionado caráter "a-histórico"; ou seja, à idéia de que essas formas de controles são "naturais e eternas", não ampliando a discussão para outras formas de controle que não a capitalista.

\section{Perspectiva sociológico-crítica}

Para darmos conta da segunda perspectiva, faremos um movimento no qual, a princípio, iremos nos afastar das teorias da administração, retornando a ela num segundo momento e tendo como base as idéias defendidas por Faria (2004a, 2004b e 2004c). Esse movimento nos possibilitará um duplo resultado: conceituar o termo controle sob um novo enfoque e apresentar a economia política do poder - perspectiva que possibilita uma apreciação crítica ${ }^{7}$ desse fenômeno nos estudos organizacionais.

\section{O controle para Braverman}

\footnotetext{
${ }^{7}$ Referindo-se à Escola de Frankfurt.
} 
Braverman (1981) e os demais autores citados adiante tratam a questão do controle de uma perspectiva de cunho mais sociológico. Por conta disso, a nosso ver, não estão interessados diretamente na questão da funcionalidade do controle e, sim, nas consequiências e condições de surgimento/desenvolvimento do controle no contexto social.

A base para o raciocínio apresentado por Braverman (1981) advém do referencial marxista. Seguindo esse referencial, o autor, em linhas gerais, tem como pretensão apresentar uma análise crítica do atual modo de produção capitalista, ou conforme suas palavras (BRAVERMAN, 1981, p.24), "neste livro nos ocuparemos inteiramente do desenvolvimento dos processos de produção e dos processos de trabalho em geral da sociedade capitalista", ou ainda (BRAVERMAN, 1981, p.31), "de qualquer modo, o propósito desse livro é o estudo dos processos de trabalho da sociedade capitalista, e do modo específico pelo qual eles são constituídos pelas relações de propriedade capitalistas". Ao realizar esse movimento, o autor é norteado pelo pressuposto de que "o atual modo de organização e controle do trabalho tenha surgido na sociedade capitalista por motivos específicos dessa sociedade." (BRAVERMAN, 1981, p.26).

Como já foi visto, a temática controle, embora central em sua análise, não é seu objeto de estudo. Dessa maneira, buscaremos extrair alguns elementos presentes no pensamento do autor em relação a essa temática. Portanto, para os fins visados neste estudo acompanharemos Braverman (1981) no seu movimento inicial, que consiste em demonstrar as raízes da atual configuração do processo de trabalho. Para tanto, como já ressaltado anteriormente, muito apoiado em Marx (1996). Nesse sentido, a contradição entre capital e trabalho e a exploração do segundo pelo primeiro são pressupostos da análise apresentada pelo autor. ${ }^{8}$ Portanto, apresentaremos, de maneira resumida, como essas idéias de contradição e de exploração do trabalho pelo capital são defendidas por Marx (1996).

Para Marx (1996), toda mercadoria possui um valor de uso e um valor de troca. O valor de uso consiste em uma característica qualitativa da mercadoria. O valor de troca, por sua vez, representa algo quantitativo, isto é, que pode ser medido. Quando uma troca ocorre, duas mercadorias com valores de troca iguais são intercambiadas. Em linhas gerais, na teoria marxista, o que determina o valor de troca é o trabalho socialmente pretendido com a produção de uma determinada mercadoria. A exploração do trabalhador e, conseqüentemente, a mais-valia, ocorrem devido a uma relação de troca, onde uma das partes não receberá o valor correspondente ao trabalho humano objetivamente adicionado à mercadoria produzida. Assim, ao vender sua força de trabalho, o trabalhador não recebe o valor total que ele adiciona a um determinado produto; recebe apenas uma parte desse valor. $\mathrm{O}$ restante do trabalho adicionado ao produto corresponde à mais-valia que fica com o capitalista.

Duas são as maneiras apresentadas, de se aumentar essa mais-valia: pela intensificação do trabalho e pela diminuição do tempo de trabalho necessário para cobrir os custos de produção. O primeiro caso, conhecido também como mais-valia absoluta consiste, basicamente, na ampliação da jornada de trabalho. Ao passo que o segundo tipo, conhecido como mais-valia relativa, consiste no encurtamento do tempo de trabalho necessário, proporcionado, por exemplo, pelo desenvolvimento de novas tecnologias de produção ou de novas ferramentas de gestão do trabalho. Vale ressaltar que para um real entendimento da sociedade capitalista e do conseqüente processo de exploração do trabalho pelo capital seria necessário acompanhar o pensamento teórico de Marx (1996) em sua totalidade, que vai da constituição da mercadoria até a análise do seu amadurecimento como capital e, seguindo esse raciocínio, abordando como a forma social de capital transforma completamente as relações sociais de produção e de vida de uma sociedade - o que foge aos objetivos deste artigo.

Braverman (1981), ao iniciar sua discussão sobre o fenômeno da gerência - e, consequentemente, do controle ${ }^{9}$ do capital sobre o trabalho na sociedade atual -, apresenta as três condições básicas que caracterizam o modo de produção capitalista e que norteiam o processo de compra e venda da força de trabalho nessa sociedade: ${ }^{10}$

Em primeiro lugar, os trabalhadores são separados dos meios com os quais a produção é realizada, e só podem ter acesso a eles vendendo sua força de trabalho a outros. ${ }^{11}$ Em segundo, os trabalhadores estão

\footnotetext{
${ }^{8} \mathrm{~A}$ exploração do trabalho pelo capital - visando à obtenção da mais-valia - é tida como um dos pressupostos que norteiam tanto o pensamento de Braverman (1981) quanto o de Faria (2004a, 2004b, 2004c).

Importante notar que, aqui, o termo controle já adquire uma conotação crítica.

${ }^{10}$ Processo que é fundamental para a exploração do trabalho pelo capital.
} 
livres de constrições legais, tais como servidão ou escravidão, que os impeçam de dispor de sua força de trabalho. Em terceiro, o propósito do emprego do trabalhador torna-se a expansão de uma unidade de capital pertencente ao empregador, que está assim atuando como capitalista. (BRAVERMAN, 1981, p. 5455)

Tendo em vista esses pressupostos, Braverman (1981) defende que o fenômeno da gerência, embora a princípio apareça como fruto da necessidade de garantir a coordenação das atividades produtivas, na sociedade capitalista, exerce um papel muito mais de controle do que de coordenação, tendo em vista assegurar os objetivos estabelecidos pelo capital na relação conflituosa entre este e o trabalho. ${ }^{12}$ Desse forma, o autor afirma que (p.59)

Torna-se portanto fundamental para o capitalista que o controle sobre o processo de trabalho passe das mãos do trabalhador para as suas próprias. Essa transição apresenta-se na história como a alienação progressiva dos processos de produção do trabalhador; para o capitalista, apresenta-se como o problema de gerência.

Interessante notar que a própria origem do verbo administrar/gerenciar contempla esses objetivos, conforme coloca Braverman (1981, p. 68):

$O$ verbo to manage (administrar, gerenciar), vem de manus, do latim, que significa mão. Antigamente significava adestrar um cavalo nas suas andaduras, para fazê-lo praticar o manège. Como um cavaleiro que utiliza rédeas, bridão, esporas, cenoura, chicote e adestramento desde o nascimento para impor sua vontade ao animal, o capitalista empenha-se, através da gerência, (management) em controlar. E o controle é, de fato, o conceito fundamental de todos os sistemas gerenciais, como foi reconhecido implícita ou explicitamente por todos os teóricos da gerência.

Conforme pode ser notado, o controle denota uma acepção "negativa", como algo relacionado à opressão ou à alienação do trabalhador, e, em síntese, é representado pelas funções de fiscalização e de ajustamento do homem à máquina organizacional através da determinação do seu fazer e do seu pensar.

Assim, modelos teóricos tidos como avanços na história da administração - como o taylorismo, o fayolismo e o fordismo - são vistos por Braverman (1981) como formas de intensificar e otimizar o controle sobre o trabalhador, como ilustrado por esta citação:

Admitia-se em geral, antes de Taylor, que a gerência tinha o direito de 'controlar' o trabalho, mas na prática esse direito usualmente significava apenas a fixação de tarefas, com pouca interferência direta no modo de executá-las pelo trabalhador. A contribuição de Taylor foi no sentido de inverter essa prática e substituí-la pelo seu oposto. A gerência, insistia ele, só podia ser um empreendimento limitado e frustrado se deixasse ao trabalhador qualquer decisão sobre o trabalho. (BRAVERMAN, 1981 p. 86)

Visto isso e procurando complementar a acepção partilhada por essa perspectiva, apresentaremos dois outros autores que compartilham em grande medida essa visão; um deles aproximando-se mais da sociologia e das ciências políticas e o outro, da teoria das organizações.

\section{O controle para Enriquez}

Enriquez (1996) discute a história da humanidade a partir de uma ótica freudiana. Nessa discussão, a sociedade, a exemplo do indivíduo, move-se num jogo constante entre os impulsos e as proibições; entre o desejo e o recalcamento. Logo, a questão do controle social perpassa toda a obra.

Dentro dessa temática podemos destacar o segundo capítulo do livro de Enriquez, no qual o autor trata da questão do poder e da dominação, bem como dos tipos de regimes políticos. O controle, nesse sentido, aparece relacionado com a manutenção do domínio exercido pelo Estado sobre o corpo social - aquilo que em última ins-

\footnotetext{
${ }^{11}$ Essa característica da sociedade capitalista está diretamente relacionada com o nível econômico de análise do controle, apresentado adiante quando é descrita a economia política do poder.

${ }^{12}$ A suposição da relação conflituosa entre capital e trabalho, típica da sociedade capitalista, traz em seu bojo elementos da verdadeira contradição dialética. A contradição dialética antecede uma superação dialética do antigo pelo novo. Como visto, tal superação, apesar do esforço teórico empenhado, não pode ser contemplada pela visão funcionalista ou mesmo sistêmica.
} 
tância garante a ordem, a manutenção das relações de poder e a execução dos objetivos do Estado. O autor apresenta-nos sete modos de controle social:

\section{Quadro 1}

\section{Formas de controle social}

CONTROLE DIRETO
(físico)

Caracterizado pela opressão e mediado pela violência. Nessa discussão, dois conceitos se tornam chave: (físico)

o de exploração - "exploração dos grupos totalmente submissos às leis do capitalismo selvagem que fazem dobrar os corpos e o coração.” (p.283)

o de repressão - "que se exprime em todos os casos de questionamento ou mesmo quando uma ameaça dessa ordem é percebida aos olhos dos dirigentes." (p. 283)

Assinalado como aquele que "prevalece no mundo das grandes organizações industriais e administrativas." (p.

CONTROLE ORGANIZACIONAL (pela máquina burocrática) 284). De maneira geral, diz respeito ao controle do trabalho e do rendimento, concretizado pelo controle do tempo, dos gestos, do comportamento e da atitude do trabalhador diante da organização

Modo mais sutil e moderno de controle, tem a competição como "pano de fundo". Apela para a iniciativa individual e para a inventividade de cada um, baseado na idéia dualística que divide os indivíduos em bons (os que cumprem objetivos) e maus (os que não cumprem os objetivos)

Busca transmitir ao povo um determinado conjunto de valores e de desejos, visando, com isso, limitar o espaço de manifestação de expressões livres ou contrárias aos interesses do Estado

Baseado nos vínculos libidinais de fascínio e sedução. O fascínio está relacionado à identificação total de um ser com outro, pela qual o ego do ser fascinado é absorvido e ampliado pelo ser fascinante. Já a sedução está relacionada com o jogo de aparências

Configurado pela monopolização da expressão do discurso social e pela censura generalizada, privando, com isso, todas as classes de seus próprios desejos e meios de expressão

Coíbe, tolhe ou ameaça pela presença. Como exemplo, podemos citar o Estado evidenciando seu aparelho de intervenção (o aparelho policial, por exemplo) ao povo, para inibir comportamentos indesejáveis

Fonte: Enriquez (1996).

Como pode ser observado, a questão do controle está, novamente, relacionada com o recalcamento e à determinação do agir do indivíduo por algo externo a ele - tolhendo-lhe a autonomia sobre seus atos e sua vida. Somado a isso, o controle passa a ter outra importante função: assegurar a manutenção das relações de poder no Estado e nas organizações. Como será evidenciado adiante, Faria (2004c) fará uso das categorias apresentadas anteriormente ao apresentar a proposta de estudo da economia política do poder. Ademais, Faria (2004c) se apoiará no referencial freudiano proposto por Enriquez para o estudo do controle num nível mais subjetivo de análise, abarcando fenômenos como a mitificação, o fascínio e a sedução.

Essa conotação atribuída ao controle é partilhada, a nosso ver, pela economia política do poder.

\section{$O$ controle para a economia politica do poder}

Segundo Faria (2004a), a economia política do poder (EPP) pode ser caracterizada como uma teoria crítica das formas de controle nas organizações capitalistas. Por teoria crítica entendemos uma determinada corrente de 
pensamento filiada à Escola de Frankfurt. Antes de entramos no conceito de controle segundo essa teoria, acreditamos ser interessante a apresentação, mesmo que resumidamente, de seus principais fundamentos.

\section{Pressupostos}

Nessa teoria, o controle tem a mesma acepção utilizada por Braverman (1981). Ele aparece como algo próximo aos termos fiscalização, recalcamento e ajustamento, ou, ainda, vigilância, repressão e determinação - tanto do agir quanto do pensar. Todavia, vale destacar que a ótica de análise e a crítica em relação ao controle é feita a partir de um referencial cujas raízes são encontradas em Marx (1996). Portanto, não é a crítica a qualquer tipo ou forma de controle, mas sim a crítica ao controle capitalista; ou seja, ao controle característico da sociedade capitalista, que tem como objetivo último a expropriação do trabalhador e a conseqüente obtenção da maisvalia, ${ }^{13}$ seja ela absoluta ou relativa.

No campo dos estudos organizacionais, acreditamos que o trabalho de Warhurst (1998) serve como exemplo da diferença entre o controle capitalista e o controle não-capitalista. Para esse estudo, o autor foi a um kibutz em Israel para estudar as formas locais de controle e organização do trabalho. Nesse contexto, ele defende que, apesar de ser uma organização com princípios comunistas - portanto, não expropriadora de mais-valia -, ela apresenta outras formas de controle que se diferem, tanto em termos de fins quanto de meios, do que normalmente é encontrado na empresa capitalista tradicional.

Partindo desses pressupostos, Faria (2004b) defende que a teoria gerencial, desde Taylor até os dias atuais, tem por base a busca do desenvolvimento de mecanismos de controle visando assegurar a extração da mais-valia e a manutenção das relações de poder. Aqui, parte-se do pressuposto que o controle é a principal forma de instrumentalização da gestão. Nesse sentido, Faria (2004c, p.86) afirma:

Como forma principal de instrumentalização da gestão do processo de trabalho, o controle traduz-se na vigilância permanente do trabalhador, no seu ritmo de trabalho, nos gestos, na postura, no cumprimento estrito das especificações do trabalho, na máxima utilidade do tempo; enfim, no adestramento do corpo e das emoções. O imperativo da gestão é controlar para produzir, sob o primado da repetição e da racionalidade do processo de trabalho. Todo tempo da produção é também o tempo do controle cerrado, exercido em cada seção, oficina ou escritório e em cada movimento, gesto ou manifestação. Só é permitido o que está previsto; só é previsto o que importa à produção dos resultados.

Em certo sentido, o controle de acordo com essa concepção abrange muito mais do que a determinação do comportamento do trabalhador: abrange a subjetividade do mesmo. "O controle implica, nessa medida, subtrair ao trabalhador as iniciativas e as decisões sobre forma (como) e quantidade (quanto) necessários à produção, impondo a opção de trabalhar ou não trabalhar nas condições dadas." (FARIA 2004c, p.86).

Dessa forma, assume-se que a organização busca criar uma realidade onde os sistemas de relações existentes sejam aqueles que foram definidos pelos dirigentes da mesma. Procura-se criar um imaginário coletivo que mascare as relações de poder e dominação, assegurando que será alcançado o objetivo do capitalista: a extração da mais valia.

Para compreender o controle de maneira mais detalhada, Faria (2004c) classifica-o em categorias, tendo por base seu nível, sua forma e suas práticas. São três os níveis categóricos determinados pelo autor: econômico, político-ideológico e psicossocial. Vale lembrar que tais formas de controle são interdependentes. Assim, o autor afirma que:

Embora cada uma das dimensões possa ser isolada para fins de análise, concretamente as mesmas aparecem como processos integrados, com suas formas e substâncias, o que exige, de imediato, uma distinção entre o controle em si e suas formas. $O$ controle em si mesmo refere-se ao processo, à sua existência, à sua substância, enquanto as formas de controle referem-se à sua ação, à execução, às maneiras como o controle é exercido e que estabelecem os padrões que o institucionalizam. Forma e substância constituem uma unidade quando se investiga os mecanismos de controle, de tal maneira que não se pode analisar o

\footnotetext{
${ }^{13} \mathrm{Em}$ linhas gerais, de acordo com o que coloca Marx (1996), a mais-valia representa a diferença entre o valor produzido pela força de trabalho e o custo de sua manutenção, que é retida pelo capitalista.
} 
controle em si sem analisar sua prática, seus efeitos e as relações entre ambos, das quais resultam novas práticas, novos efeitos e novas relações. (FARIA 2004c, p.89)

De modo geral, o controle econômico refere-se às relações de produção, em especial às relações e aos processos de trabalho, no que concerne à propriedade e à posse. Nessa discussão são destacadas as implicações da intensificação das mudanças na relação de propriedade e de posse dos meios de produção - principalmente, no que diz respeito ao processo de apropriação dos meios e objetos de trabalho pelo capitalista - que se intensificaram com o surgimento da sociedade capitalista. Para o autor, essa mudança está diretamente relacionada com o processo de controle e determinação da produção (determinação do que deve ser feito e de como deve ser feito) e do conseqüente aumento da exploração do trabalhador.

Dois tipos de relação de propriedade são destacados: a propriedade legal e a propriedade real. De maneira resumida, a propriedade legal diz respeito ao controle sobre o investimento e a acumulação do capital (os acionistas, por exemplo). Já a propriedade real refere-se à "relação de propriedade econômica (controle sobre o que é produzido, inclusive sobre a capacidade de dispor do produto) e relações de posse" (controle sobre como é produzido). (FARIA, 2004c, p.90).

Por sua vez, o nível político-ideológico "diz respeito à superestrutura construída a partir das relações de produção, especialmente às relações de posse, sua institucionalização, inclusive no âmbito do Estado e seus aparelhos, e de todo o aparato normativo, tendo como suporte um sistema de idéias capazes de conferir legitimidade às ações." (FARIA, 2004c, p.88-89).

Dessa forma, o controle relaciona-se diretamente com as relações de dominação, que em última instância visam legitimar e garantir a permanência das relações de posse e de poder. Os elementos dessa categoria foram buscados nas teorias administrativas e que, de acordo com Faria (2004c, p.98), são "o despotismo e suas manifestações, o sistema disciplinar dos agentes, uma rígida estrutura hierárquica, os processos de transmissão da ideologia, a alienação e as formas sutis de submissão.”

Por fim, o nível psicossocial "diz respeito às relações entre os sujeitos, sejam estes individuais ou coletivos, inseridos nos processos produtivos e políticos." (FARIA, 2004c, p.89). Nesse nível o autor estabelece, baseado em Enriquez (1996), sete categorias classificatórias do controle, conforme o quadro 2: 


\section{Quadro 2}

\section{Dimensões do controle psicossocial segundo Faria}

FÍSICO - baseado no domínio do corpo do indivíduo ou do grupo social. Age através da violência, da exploração, de toda sorte de concessões ou impedimentos, de permissões e proibições, de definição (ocupação) de espaços e de movimentos, de delimitação de tempo e natureza do trabalho. O controle físico está na divisão social e técnica do trabalho, na vigilância, nas formas de relacionamento social (trajes, atitudes, posturas) e no desempenho

NORMATIVO - diz respeito ao conjunto de regras, normas e dispositivos formais e às regulamentações não explicitadas mas entendidas pelos sujeitos como definidoras de condutas que regem a ordem organizacional. $\mathrm{O}$ controle normativo define tanto os procedimentos burocráticos como suas atribuições de autoridade e responsabilidade, assim como as convenções que geram obediência e aceitação por imposição de natureza moral ou defensiva

FINALÍSTICO ou POR RESULTADO - refere-se ao controle que busca garantir o cumprimento da finalidade econômica e política da organização, sua ação material e seus resultados, através do estabelecimento de metas e objetivos e da criação de compromissos, especialmente aqueles que configuram sentimentos de cumplicidade.

COMPARTILHADO ou PARTICIPATIVO - refere-se à busca da legitimidade da ação através da construção e da manutenção de convicções e de procedimentos tidos como éticos, seja pelo envolvimento do conjunto dos participantes no processo decisório ou pelo estabelecimento de sistemas de comando representativos. O controle compartilhado ou participativo é evidenciado nas formas de definição das estruturas de gestão (inclusive, quanto à composição dos cargos e funções administrativas) e nos encaminhamentos dos planos e das estratégias de ação

SIMBÓLICO-IMAGINÁRIO - diz respeito aos processos de adesão imaginária, ao desenvolvimento de modelos de comportamentos tidos como referências, às formas de competição interna, às crenças e suposições concretas ou fictícias, às adesões representadas por reconhecimento ou prestígio, à instauração de aparelhos de intervenção que funcionam pela ameaça do uso de força e por demonstrações de domínio dos aparatos coercitivos (sem necessidade de utilizá-los), pelos discursos conciliadores e pela valorização de símbolos representativos de sucesso ou de fracasso que devem direcionar as atitudes esperadas

POR VÍNCULO - refere-se à concepção de um projeto social comum, atuando através de contratos formais ou psicológicos, dos interesses e das necessidades, do amor, da ternura, da libido, da identificação subjetiva ou inconsciente, da expressão de confiança nos desígnios da organização, das transferências egoístas e do fascínio, na medida em que os sujeitos desejam o vínculo para se inscreverem no campo do outro

POR SEDUÇÃO MONOPOLISTA - caracterizado pelo discurso único, pela coesão primária (grande família, colaboradores), pela realização de um poder sem projeto que uniformiza e monopoliza o discurso e a censura, retirando dos grupos e dos indivíduos sua voz e sua existência e tornando-os apáticos, submissos, conformados ou totalmente crédulos e confiantes na condição monopolista dos dirigentes como detentores das melhores alternativas de condução da organização

Fonte: Faria (2004b, p.130-131).

Como pôde ser notado, o estudo do controle ganha novo corpo, sendo visto não mais como um ferramental tendo por função a coordenação. A intencionalidade e a forma de controle (por vezes agressiva e prejudicial ao corpo social) são desvelados.

Acreditamos que os desdobramentos dessas reflexões podem levar os estudos organizacionais a um novo direcionamento, no sentido de um questionamento da própria estruturação social, e em direção a outras formas de organização social e controle.

\section{Estudos organizacionais e a perspectiva sociológico-crítica}

Embora a perspectiva funcionalista ainda seja a predominante no estudo do controle organizacional, pode-se notar um movimento em direção à perspectiva sociológico-crítica. Nesse sentido, visando ampliar nossa discussão, apresentaremos alguns estudos (nacionais e internacionais) que se enquadram nessa perspectiva.

Como um primeiro estudo dentro desse enquadramento, podemos citar Covaleski et. Al. (1998), que, a partir de uma pesquisa etnográfica, examinou como as organizações, por meio de técnicas de controle como a adminis- 
tração por objetivos, transformam profissionais em membros organizacionais auto-disciplinados cujos objetivos de trabalho, linguagem e estilo de vida tornam-se reflexos dos imperativos das organizações.

Sewell (1998), por sua vez, também partindo de um referencial crítico, interessou-se pela questão das equipes de trabalho. Nesse sentido, em linhas gerais, contrapôs a idéia de que essas equipes são sinônimo de autonomia para os trabalhadores, como é defendido tradicionalmente pela teoria organizacional. Contrariando dessa idéia, ele mostrou como, a partir de novas formas de vigilância, o controle hierárquico tradicional é substituído por novas formas de controle muitas vezes mais sutil, mas, ainda assim, existentes e com poder de manipular subjetividades.

Outro interessante estudo a ser citado é o de Oakes, Townley e Cooper (1998), que baseados nos trabalhos de Bourdieu, defendem que o plano de negócios (técnica tida como racional e neutra) é um instrumento pedagógico de controle, que exerce, no limite, influência na própria identidade profissional dos trabalhadores.

Por fim, no contexto nacional, podemos destacar os trabalhos de Silva (2000) e de Silva e Alcadipani (2003). Silva (2000) realizou uma interessante investigação acerca das conseqüências da implementação da gestão da qualidade total (CGT) sobre o controle organizacional a partir de um estudo de caso realizado na Siderúrgica Riograndense. Ao longo dessa pesquisa, a autora confirmou a hipótese de que a implementação da CGT reforça os aspectos do controle através da cultura organizacional.

Já Silva e Alcadipani (2003), ao reverem alguns dos resultados apresentados em Silva (2000), aproximam-se ainda mais do referencial sociológico-crítico aqui defendido. Dessa forma, a partir de uma releitura dos resultados anteriores, à luz de Foucault, perseguem o objetivo de analisar as transformações do controle organizacional. Assim, traçam um paralelo entre o estudo de Foucault (1987) e as mudanças no controle organizacional verificadas no estudo de caso anteriormente citado. Desse modo, evidenciaram no caso analisado a transformação do regime de controle caracterizado pela punição para um regime de controle caracterizado pela disciplina, a exemplo do movimento ocorrido nos regimes de controle da sociedade em geral e descrito por Foucault (1987).

Entretanto, apesar desses autores fazerem um corte analítico diferenciado (em comparação com a teoria organizacional em voga), vale ressaltar que seus pressupostos (embora apresentem um olhar crítico) divergem em grande medida dos pressupostos teóricos e filosóficos da economia política do poder, tendo em vista que, como foi dito aqui, esta se fundamenta no trabalho dos teóricos de Frankfurt e, portanto, numa perspectiva epistemológica diversa daquela que sustenta os trabalhos fundamentados em Foucault, por exemplo. ${ }^{14}$

Gostaríamos ainda de destacar o evidente preconceito, no campo organizacional, em relação a essas idéias de cunho mais crítico ${ }^{15} \mathrm{e}$, particularmente, em relação às teorias embasadas num referencial marxista. Tal preconceito pode ser justificado pelo próprio poder transformador dessas idéias, dado que a partir do momento em que são aceitas, não há mais como tapar os olhos para os efeitos maléficos de algumas das técnicas administrativas, direcionando os administradores para novos rumos que, em sua grande maioria, para o grande público, são tidos como nebulosos e ameaçadores.

\section{Considerações finais}

Este artigo procurou discutir o controle a partir de duas diferentes perspectivas de análise. Nesse sentido, o termo foi definido, antes de tudo, de acordo com autores próximos à área organizacional, onde a discussão coloca o controle como uma ferramenta gerencial ou como parte de um corpo organizacional responsável por garantir a coordenação e integração dos indivíduos e o aprimoramento da organização diante do ambiente. O controle é visto como uma variável operatória que tem por objetivo garantir e aperfeiçoar o funcionamento do sistema or-

\footnotetext{
${ }^{14}$ Embora essa discussão ultrapasse os limites deste artigo, vale destacar que, a nosso ver, a partir do momento em que esses autores aproximam-se, em alguma medida, de um referencial pós-modernista, suas possibilidades de conversação com a economia política do poder (teoria com raízes marxistas) tornam-se limitadas, como nos mostram, por exemplo, Wood (1999) e Evangelista (1997). Wood (1999, p.15), ao analisar a perspectiva pós-moderna em face da perspectiva marxista, evidencia essa impossibilidade ao afirmar que "uma vez que não há sistemas ou história suscetível à análise causal [na perspectiva pós-moderna], não podemos chegar à origem dos muitos poderes que nos oprimem. Nem tampouco, certamente, aspirar a algum tipo de oposição unificada de emancipação humana em geral", o que entra em contradição com os pressupostos fundamentais e com a proposta política da economia política do poder.

${ }^{15} \mathrm{Em}$ especial quanto às idéias oriundas da teoria crítica. Vale ressaltar que teoria crítica é diferente de crítica teórica.
} 
ganizacional; portanto como um instrumento de coordenação ou ajustamento. Da segunda perspectiva, o controle é tido como aquilo que - através da opressão, do recalcamento e da alienação - assegura a dominação e a manutenção das relações de poder. Todavia, como já foi defendido, pouca ênfase têm sido dada nas teorias organizacionais à segunda perspectiva. A nosso ver, isso ocorre devido ao caráter dominante do funcionalismo nas teorias administrativas. Não queremos aqui tirar os méritos desse paradigma, mas não podemos deixar de apontar para o caráter dominante e pretensioso que alguns teóricos têm atribuído a esse ponto de vista.

Portanto, as teorias de cunho crítico têm sido secundarizadas nos estudos organizacionais. Por conta disso, acreditamos que tais estudos vêm se tornando meros reprodutores de técnicas gerencialistas, deixando de lado reflexões de cunho filosófico-sociológico pertinentes a essa área do saber. Nesse sentido, técnicas são criadas sem que se permita o questionamento sobre sua utilidade e o(s) grupo(s) que dela se beneficiará (beneficiarão) e que a elas terá (terão) acesso. A economia política do poder surge, então, como uma resposta a esse paradigma e vem mostrar-nos que uma reflexão nesse nível é, além de pertinente, necessária, visto que, a nosso ver, o questionamento acerca das funções a serem desempenhadas pelas técnicas e instrumentos administrativos deve, preferivelmente, preceder a sua criação. 


\section{Referências}

BRAVERMAN, H. Trabalho e capital monopolista: a degradação do trabalho no século XX. Rio de Janeiro: Zahar Editores, 1981.

BURREL, G.; MORGAN, G. Sociological paradigms and organizational analysis. London: Heineman; 1979.

CHANLAT, J.; SĖGUIN, F. L'analyse dês organisations: une anthologie sociologique. Montreal: Gaëtan Morin, 1987. p.33-36.

COVALESKI, M.A et al. The calculated and the avowed: techniques of discipline and struggles over identity in big six public accounting firms. Administrative Science Quarterly, v.2, n.43, p.293-327, June 1998.

DAVEL, E.; ALCADIPANI, R. Estudos críticos em administração: a produção científica brasileira nos anos 1990. Revista de Administração de Empresas, v.43, n.4, p.72-85, out./nov. 2003.

DEMO, P. Metodologia científica em ciências sociais. São Paulo: Atlas, 1995.

DURKHEIM. Da divisão social do trabalho. São Paulo: Abril Cultural, 1978. p.1-70. (Coleção Os Pensadores).

ENRIQUEZ, E. Da horda ao Estado: psicanálise do vínculo social. Rio de Janeiro: Jorge Zahar, 1996.

ETZIONI, A. Organizações modernas. São Paulo: Livraria Pioneira Editora, 1967.

EVANGELISTA, J. E. Crise do marxismo e irracionalismo pós-moderno. São Paulo: Cortez, 1997.

FARIA, J. H. O autoritarismo nas organizações. Curitiba: Criar Edições/FAE, 1985.

Economia política do poder: as práticas do controle nas organizações. Curitiba: Juruá, $2004 a$.

Economia política do poder: uma crítica da teoria geral da administração. Curitiba: Juruá, $2004 b$.

Economia política do poder: os fundamentos da teoria crítica nos estudos organizacionais. Curitiba: Juruá, 2004c.

FOUCAULT, M. Vigiar e punir: nascimento da prisão. Petrópolis: Vozes, 1987.

HATCH, M. J. Organization theory: modern, symbolic and postmodern perspectives. New York: Oxford University Press, 1997.

JERMIER, J.M. Introduction: critical perspectives on organizational control. Administrative Science Quarterly, v.2, n.43, p.235-256, June 1998.

MALINOWISK, B.K. Argonautas do Pacífico ocidental: um relato do empreendimento e da aventura dos nativos nos arquipélagos da Nova Guiné Melanésia. São Paulo: Abril Cultural, 1978. (Coleção Os Pensadores).

MARX, K. O Capital: crítica da economia política. São Paulo: Editora Nova Cultural. 1996. v.1. (Coleção Os Economistas).

MORGAN, G. Imagens da Organização. São Paulo: Atlas, 1999.

MOTTA, F. C. P. Controle social nas organizações. Revista de Administração de Empresas, São Paulo, v.19, n.3, p.11-25, jul./set. 1979.

. 0 autonomismo e a questão da organização. Revista de Administração de Empresas, São Paulo, v.26, n.1, p.57-66, jul./set. 1986.

OAKES, L. S.; TOWNLEY, B.; COOPER, D. J. Business planning as pedagogy: language and control in a changing institutional field. Administrative Science Quarterly, v.2, n.43, p.257-292, June 1998.

OLIVEIRA, D. P. R. Planejamento estratégico: conceitos, metodologia e prática. São Paulo: Atlas, 2003.

PARSONS, T. Sociedades: perspectivas evolutivas e comparativas. São Paulo: Livraria Pioneira Editora, 1969.

RADCLIFFE-BROWN, A. R. Estrutura e função na sociedade primitiva. Petrópolis: Vozes, 1973.

SERVA, M., JAIME JÚNIOR, P. Observação participante e pesquisa em administração, uma postura antropológica. Revista de Administração de Empresas, São Paulo, v.35, n.1, maio/jun.1995.

SEWELL, G. The discipline of teams: the control of team-based industrial work through electronic and peer surveillance. Administrative Science Quarterly, v.2, n.43, p.397-428, June 1998.

SILVA, R. C. Mudança no controle organizacional através da implantação da gestão da qualidade total - o caso da Siderúrgica Riograndense. In: ENCONTRO ANUAL DA ANPAD, 24., 2000, Florianópolis. Anais... Curitiba: ANPAD, 2000. CD-ROM

; ALCADIPANI, R. "Manda quem pode, obedece que tem juízo" - a consolidação da disciplina através da participação na Siderúrgica Rio-Grandense. In: ENCONTRO ANUAL DA ANPAD, 27., 2003, Atibaia, SP. Anais... Curitiba: ANPAD, 2003. CD-ROM

TANNENBAUM, A. S. 0 controle nas organizações. Petrópolis: Vozes, 1975.

WARHURST, C. Recognizing the possible: the organization and control of a socialist labor process. Administrative Science Quarterly, v.43, n.2, p.470- 497, 1998 .

WOOD, E. M. 0 que é a agenda "pós-moderna". In: de Janeiro: Jorge Zahar, 1999. p.7-22.

$\therefore$ FOSTER, J. B. (Org.). Em defesa da história: marxismo e pós-modernismo. Rio

WRIGHT, P.; KROLL, M. J.; PARNEL, J. Administração estratégica. São Paulo: Atlas, 2000. 